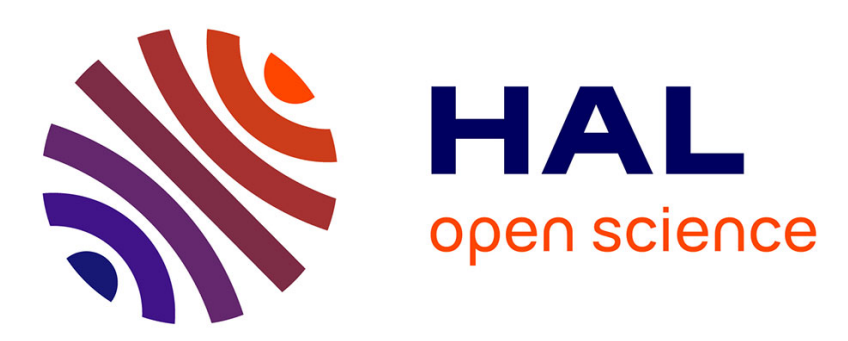

\title{
A both Gaussian and sinusoidal phase-to-amplitude converter for low-power ultra-high-speed direct digital synthesizers
}

Teddy Borr, Julien Juyon, Éric Tournier

\section{- To cite this version:}

Teddy Borr, Julien Juyon, Éric Tournier. A both Gaussian and sinusoidal phase-to-amplitude converter for low-power ultra-high-speed direct digital synthesizers. NEWCAS, Jun 2011, Bordeaux, France. pp.5-8, 10.1109/NEWCAS.2011.5981205 . hal-00713855v2

\section{HAL Id: hal-00713855 \\ https://hal.science/hal-00713855v2}

Submitted on 3 Jul 2012

HAL is a multi-disciplinary open access archive for the deposit and dissemination of scientific research documents, whether they are published or not. The documents may come from teaching and research institutions in France or abroad, or from public or private research centers.
L'archive ouverte pluridisciplinaire HAL, est destinée au dépôt et à la diffusion de documents scientifiques de niveau recherche, publiés ou non, émanant des établissements d'enseignement et de recherche français ou étrangers, des laboratoires publics ou privés. 


\title{
A both gaussian and sinusoidal phase-to-amplitude converter for low-power ultra-high-speed Direct Digital Synthesizers
}

\author{
Teddy Borr*†, Julien Juyon* ${ }^{* \dagger \dagger}$, Éric Tournier* ${ }^{* \dagger}$ \\ ${ }^{*}$ CNRS ; LAAS \\ 7 avenue du colonel Roche, \\ F-31077 Toulouse, France \\ †Université de Toulouse \\ UPS, LAAS \\ F-31077 Toulouse, France \\ $\ddagger$ AXESS Europe \\ 3 Avenue Didier Daurat \\ F-31077 Toulouse, France
}

\begin{abstract}
This paper introduces a new bipolar differential pair topology for both gaussian and sinusoidal signal shaping, to be used as a phase-to-amplitude converter alternative in lowpower ultra-high-speed DDS. A DDS using this converter, with a 9-bit frequency resolution and an 8-bit amplitude resolution has been designed in a $0.13 \mu \mathrm{m}$ SiGe BiCMOS technology, with $f_{t} / f_{\max }$ of $200 / 250 \mathrm{GHz}$, and simulated up to a $20 \mathrm{GHz}$ operating clock frequency. It consumes $585 \mathrm{~mW}$ under a $2.8 \mathrm{~V}$ power supply. Simulated triangle shape allows an optimal SFDR of $-44.5 \mathrm{dBc}$ in sinus mode and a SLRR of $-43.5 \mathrm{dBc}$ in gaussian mode.
\end{abstract}

\section{INTRODUCTION}

Direct digital synthesis is a technique which allows generation of arbitrary waveforms from a fixed frequency reference. Traditional DDS architecture [1] is made up of three main blocks as depicted on fig. 1. The DDS first accumulates a programmed phase increment $\Delta \varphi$ through a Phase Accumulator (PA) to make a digital phase ramp used to address a memory (generally a ROM) which contains the digital samples of the signal to be generated: it acts as a Phase-to-Amplitude Converter (PAC). Near the end, the digitally formatted signal is converted to analog by a linear Digital-to-Analog Converter (DAC). The main characteristics of the DDS are: fast-settling time of about one clock period, frequency resolution directly related to the phase accumulator resolution, and wideband behavior with digital modulation capabilities [2]. All these advantages make the DDS an interesting candidate for modern microwave applications. However, ROM are known to consume a large amount of area and power, which are prohibitive for embedded systems. To overcome this, a trade-off on the diversity of waveforms that can be generated had to be made in order to suppress the ROM. Thus, high-speed DDS are focused on sine wave generation [3], [4], [5] and are then able to reach only a few hundred $\mathrm{mW}$ on low-cost SiliconGermanium technologies [6], [7].

Our work intends to regain a part of the "arbitrary waveform generator" aspect of DDS by proposing a reconfigurable PAC which, when coupled to a DDS, is able to generate either sinusoidal or gaussian shaped waves. Such DDS could then be used in UWB transceivers since IR-UWB emitters use gaussian shaped pulses, while traditional receivers use sinus signals through mixers for frequency up and down conversion.

\section{ROM-LESS DDS ARCHITECTURE}

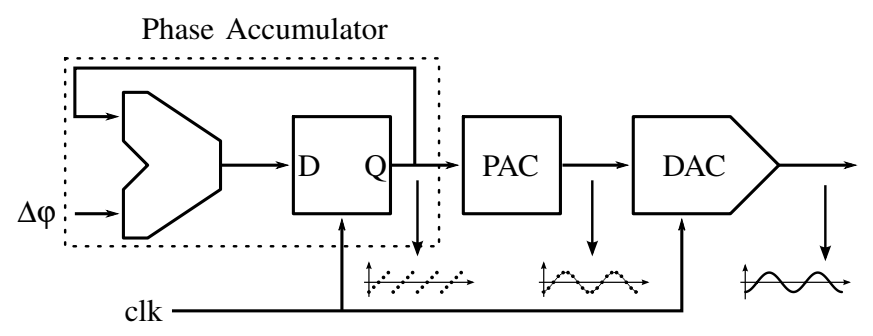

Fig. 1: Typical DDS architecture

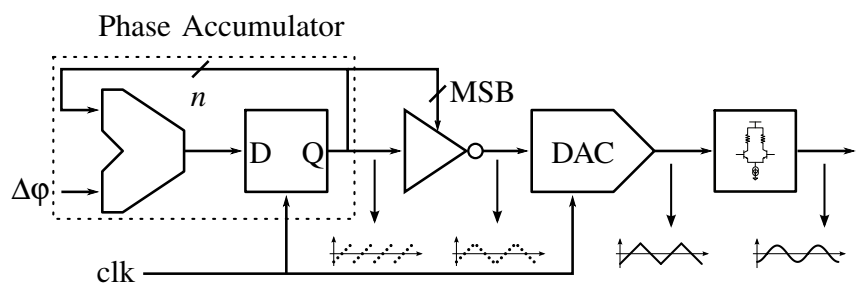

Fig. 2: ROM-less DDS architecture

It has already been shown that the hyperbolic tangent characteristic of bipolar transistors pairs is suitable to approximate either sine wave [8] or gaussian shaped [9] functions. A DDS architecture based on such a behavior has previously been reported [10]. This architecture, shown fig. 2, and compared to the classical one on fig. 1 uses a $n-1$-bit inverter between the PA and the DAC, while the PAC has been moved from the digital to the analog part after the DAC. The added inverter, driven by the MSB of the PA, transforms the digital PA's ramp to a digital triangular signal. This digital triangular signal is analog converted by the DAC, and then shaped by the analog PAC in order to fit the requested signal (in this case only a sine wave). This ROM-less architecture and its analog shaping technique have the advantage to decrease the circuit 
complexity and hence to save power consumption. The PAC presented in this paper cumulates the possibility to generate both a gaussian shape and a sine wave through a simple reconfiguration technique. A DDS with a 9-bit pipeline PA, a $2 \times 4$-bit plus 1-bit accumulator scheme, a 8-bit currentsteering linear DAC, and this new PAC has then been designed in a 3-stage Emitter-Coupled-Logic.

\section{Phase-to-Amplitude Converter}

The Gaussian/Sinus Phase-to-Amplitude Converter (G/SPAC) proposed on fig. 3 is made up of two differential pairs of bipolar transistors $\left(Q_{1}, Q_{2}\right)$ and $\left(Q_{3}, Q_{4}\right)$, both biased at the same current $\left(I_{p}\right)$ and with the same voltage reference $\left(V_{a}\right)$.

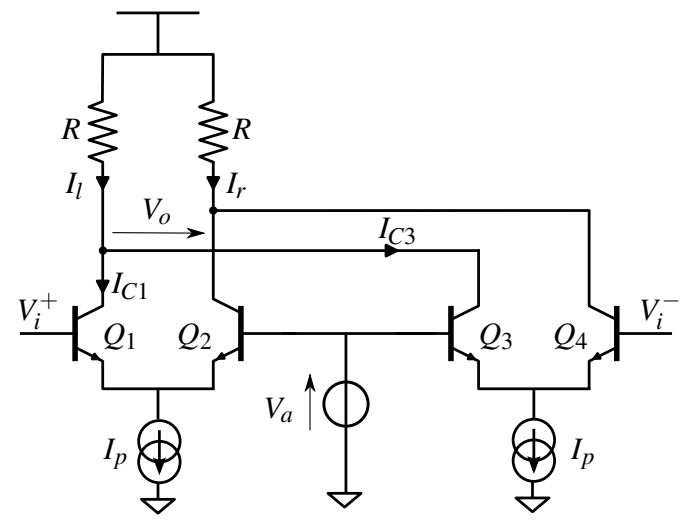

Fig. 3: Schematic of the G/S-PAC

The G/S-PAC is driven in large-signal conditions with a differential triangular signal $\left(V_{i}^{+}-V_{i}^{-}\right)$generated by the DDS. The circuit is biased and routed in such a way that a positive (negative) gaussian pulse is generated at G/S-PAC output for the positive (negative) part of the triangular input signal (fig. 4).

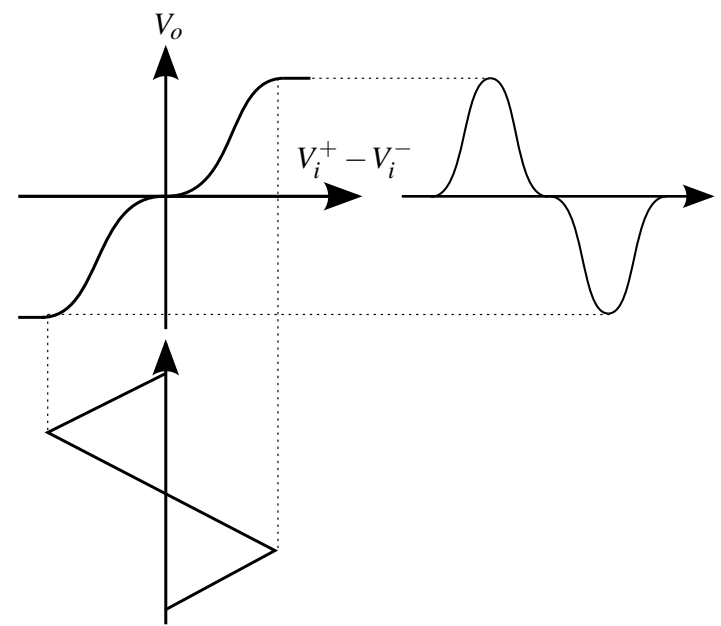

Fig. 4: Principle of the triangle-to-gaussian conversion

According to Kirchhoff law, the left branch current $I_{l}$ of the $\mathrm{G} / \mathrm{S}-\mathrm{PAC}$ circuit is

$$
I_{l}=I_{C 1}+I_{C 3}
$$

As a first approximation, we can assume Ebers-Moll model for bipolar transistors. With a forward gain $\alpha_{F}=1$, equation (1) becomes

$$
I_{l}=\frac{I_{p}}{2}\left[2+\tanh \left(\frac{V_{i}^{+}-V_{a}}{2 U_{T}}\right)+\tanh \left(\frac{V_{a}-V_{i}^{-}}{2 U_{T}}\right)\right]
$$

In the same way, the right branch current $I_{r}$ is

$$
I_{r}=\frac{I_{p}}{2}\left[2-\tanh \left(\frac{V_{i}^{+}-V_{a}}{2 U_{T}}\right)-\tanh \left(\frac{V_{a}-V_{i}^{-}}{2 U_{T}}\right)\right]
$$

Considering the differential output voltage $V_{o}$ as the product between load resistor $R$ and the differential current $I=I_{l}-I_{r}$, equations (2) and (3) give the sum of input/output relationships in large signal condition for differential amplifiers following hyperbolic tangent law

$$
V_{o}=R I_{p}\left[\tanh \left(\frac{V_{i}^{+}-V_{a}}{2 U_{T}}\right)+\tanh \left(\frac{V_{a}-V_{i}^{-}}{2 U_{T}}\right)\right]
$$

Introducing variables

- $V_{i}=V_{i}^{+}-V_{i}^{-}$as differential mode input voltage,

- $V_{c}=\left(V_{i}^{+}+V_{i}^{-}\right) / 2$ as common mode input voltage,

- $a=2\left(V_{a}-V_{c}\right)$,

and re-injecting these in equation (4) leads to the direct relation between differential output voltage $V_{o}$, input differential voltage $V_{i}$ and the introduced parameter $a$

$$
V_{o}=R I_{p}\left[\tanh \left(\frac{V_{i}-a}{4 U_{T}}\right)+\tanh \left(\frac{V_{i}+a}{4 U_{T}}\right)\right]
$$

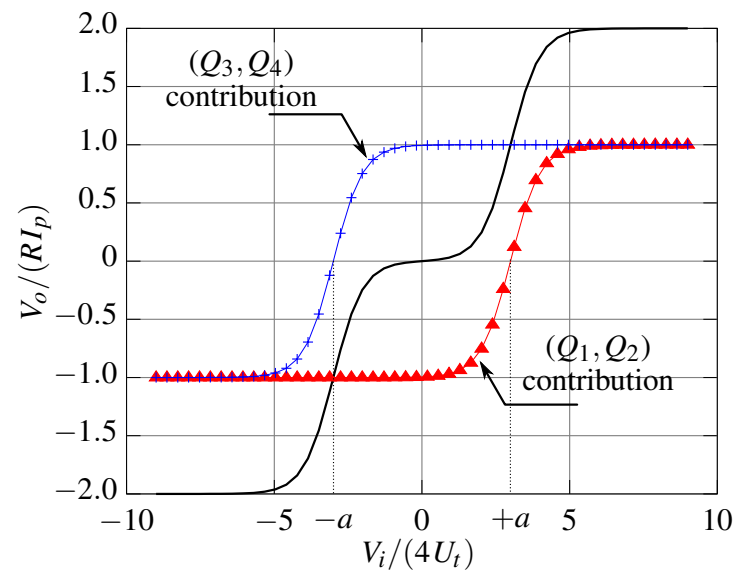

Fig. 5: Normalized input/output G/S-PAC's transfer characteristic.

Equation (5) and each of its tanh components showing two distinct saturation levels are plotted fig. 5. The proposed structure uses the " $a$ " parameter to shift both tanh characteristics by $\pm a$ along the horizontal $V_{i} /\left(4 U_{T}\right)$ axis. Thus, with " $a$ " properly chosen, a positive differential input voltage sets up $\left(Q_{3}, Q_{4}\right)$ in positive saturation while $\left(Q_{1}, Q_{2}\right)$ pair imposes its tanh behavior. Likewise, a negative input voltage sets up $\left(Q_{1}, Q_{2}\right)$ in negative saturation while $\left(Q_{3}, Q_{4}\right)$ pair imposes its tanh behavior. Thereby, by applying a differential triangular input voltage, the positive (or negative) side gives a good 
approximation of a gaussian pulse by hyperbolic tangent. Moreover, if " $a$ " is chosen equal to zero, $V_{o}$ can be rewritten as

$$
V_{o}=2 R I_{p} \tanh \left(\frac{V_{i}}{4 U_{T}}\right)
$$

Thus, $a=0$ (i.e. $V_{a}=V_{c}$ ) leads to a pure tanh behavior for the G/S-PAC. With amplitude of $V_{i}$ properly chosen, the differential triangular input voltage is curved, following tanh law, to approximate a sine wave.

\section{Simulations And Results}

In order to properly set up the amplitude of the triangular input voltage applied by the DDS to the G/S-PAC, an ideal triangular signal generator has been used to drive the G/S-PAC in optimization simulations. The well-known bell shaped frequency spectrum of generated gaussian pulses is plotted fig. 6 for various amplitude of G/S-PAC input voltage.

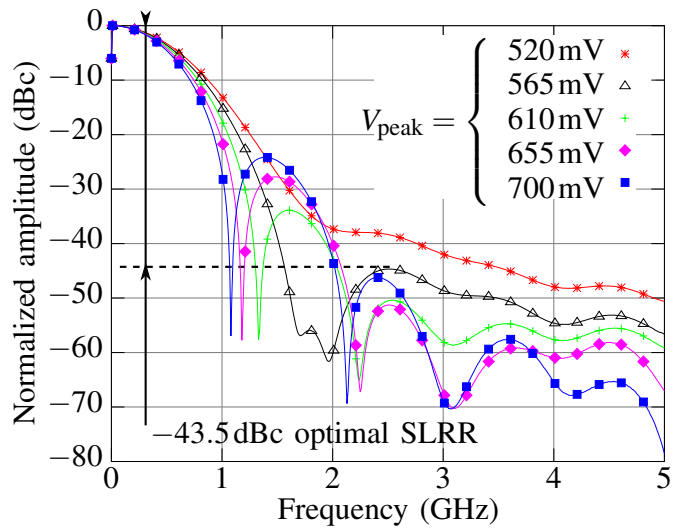

Fig. 6: Frequency spectrum of gaussian shaped pulses for various peak amplitudes from an ideal generator.

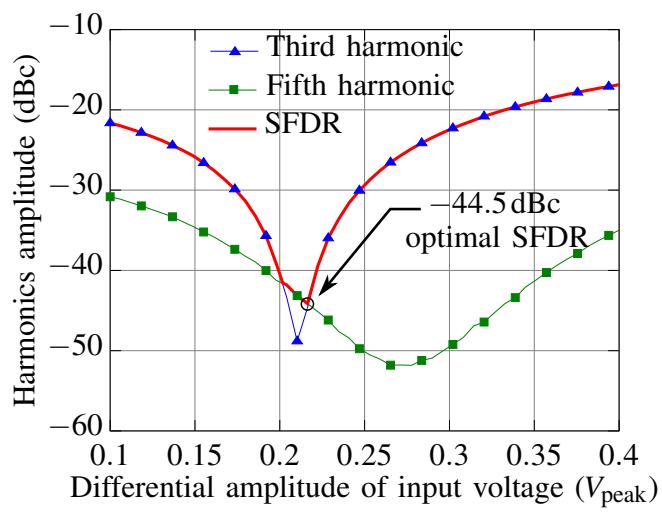

Fig. 7: Sinus' harmonics and resulting SFDR versus peak amplitude of input voltage from an ideal generator.

The tanh approximation introduces side-lobes that can be minimized to a Side Lobes Rejection Ratio (SLRR) of $-43.5 \mathrm{dBc}$ for an input peak amplitude voltage of $565 \mathrm{mV}$ obtained with $V_{c}=1.59 \mathrm{~V}$ and $V_{a}=1.77 \mathrm{~V}$. The same optimisation is made for the sinus-mode. The third and the fifth harmonics of the generated sinus are plotted fig. 7 versus the triangle amplitude. An optimal Spurious Free Dynamic Range (SFDR) of $-44.5 \mathrm{dBc}$ can be reached for a peak amplitude voltage of $220 \mathrm{mV}$ obtained with $V_{c}=V_{a}=1.79 \mathrm{~V}$.

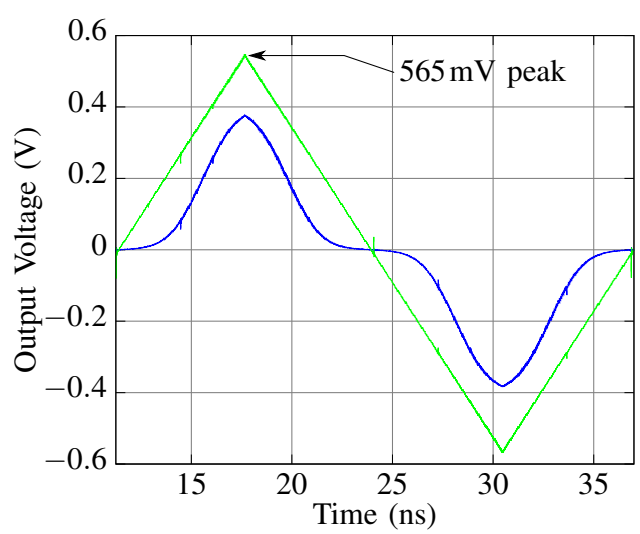

Fig. 8: Transient simulation for gaussian-mode G/S-PAC driven by a DDS with phase increment of 1 and $F_{c l k}=20 \mathrm{GHz}$

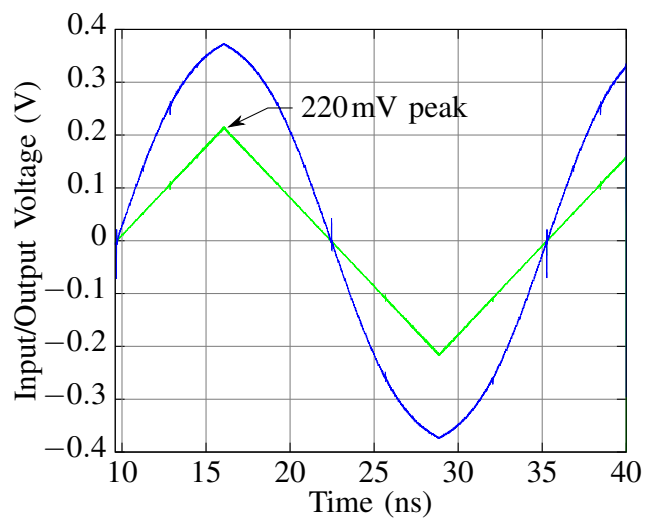

Fig. 9: Transient simulation for sinus-mode G/S-PAC driven by a DDS with phase increment of 1 and $F_{\text {clk }}=20 \mathrm{GHz}$

The G/S-PAC proposed in this paper has been used to design a first version of a 9-bit ROM-less DDS in the IBM $0.13 \mu \mathrm{m}$ BiCMOS SiGe process. This technology provides high-performance HBT with $f_{t} / f_{\max }$ of $200 / 250 \mathrm{GHz}$. Obviously, our G/S-PAC require a calibration phase. In order to reach optimal performances in future measurements, the DAC of the DDS architecture has been designed with a voltage controlled output amplitude. Since SFDR and SLRR depend on DAC linearity and matching of components, the analog part of the circuit's layout has been focused on these two main constraints.

The full circuit has been simulated with BSIM4 model for MOS transistors and VBIC model for HBT with process parameters filled from the BiCMOS8HP design kit to Spectre simulator under Cadence 5.1.41. The DDS has been simulated at a maximum operating clock frequency of $20 \mathrm{GHz}$ and consumes only $585 \mathrm{~mW}(209 \mathrm{~mA}$ under $2.8 \mathrm{~V})$. Such a consumption should be considered low for DDS and can be compared to those of others in tab. I, in which our DDS exhibit a high FOM. Further optimizations should improve this consumption. 
TABLE I: Comparison of differents ultra high-speed DDS

\begin{tabular}{|c|c|c|c|c|c|c|c|c|c|}
\hline Ref. & $\begin{array}{c}\text { Technology } \\
\text { process }\end{array}$ & $\begin{array}{c}f_{t} \mathrm{NPN} \\
(\mathrm{GHz})\end{array}$ & $\begin{array}{c}\text { Clock freq. } \\
(\mathrm{MHz})\end{array}$ & $\begin{array}{c}\text { Acc. size } \\
\text { (bit) }\end{array}$ & $\begin{array}{c}\text { Accumulator } \\
\text { decomposition }\end{array}$ & $\begin{array}{l}\text { Power } \\
(\mathrm{mW})\end{array}$ & $\begin{array}{c}\text { Die area } \\
\left(\mathrm{mm}^{2}\right)\end{array}$ & $\begin{array}{c}\text { FOM } \\
\frac{\mathrm{MHz} \times \mathrm{bit}}{\mathrm{mW} \times \mathrm{mm}^{2}}\end{array}$ & $\begin{array}{l}\text { FOM } \\
\frac{\mathrm{MHz}}{\mathrm{mW}}\end{array}$ \\
\hline [11] & $0.35 \mu \mathrm{m} \mathrm{SiGe}$ & 60 & 1700 & 32 & & 3000 & 24 & 0.76 & 0.57 \\
\hline [12] & $0.35 \mu \mathrm{m}$ CMOS & & 2000 & 8 & & 820 & 3.99 & 4.89 & 2.44 \\
\hline$[13]$ & $1 \mu \mathrm{m}$ bipolar & 22 & 2500 & 31 & $1 \times 31$ & 5000 & 20 & 0.78 & 0.5 \\
\hline [14] & $0.35 \mu \mathrm{m} \mathrm{SiGe}$ & 47 & 5000 & 8 & $8 \times 1$ & 2000 & 2 & 10 & 2.5 \\
\hline [15] & Bipolar InP & 137 & 9200 & 8 & $8 \times 1$ & 15000 & 40 & 0.12 & 0.61 \\
\hline [5] & Bipolar InP & 300 & 13000 & 8 & $1 \times 8$ & 5420 & 3.92 & 4.90 & 2.4 \\
\hline [16] & Bipolar InP & 300 & 32000 & 8 & $4 \times 2$ & 9450 & 3.92 & 6.91 & 3.39 \\
\hline$[6]$ & $0.25 \mu \mathrm{m} \mathrm{SiGe}$ & 70 & 6000 & 9 & $1 \times 9$ & 308 & 1 & 175.32 & 19.48 \\
\hline [17] & $0.09 \mu \mathrm{m}$ CMOS & & 1300 & 24 & $6 \times 4$ & 350 & 2 & 44.6 & 3.71 \\
\hline$[18]$ & $0.35 \mu \mathrm{m} \mathrm{SiGe}$ & 200 & 15000 & 8 & $4 \times 2$ & 366 & 1.16 & 282.76 & 40.98 \\
\hline This work (simulated) & $0.13 \mu \mathrm{m} \mathrm{SiGe}$ & 200 & 20000 & 9 & $1+2 \times 4$ & 585 & 1.32 & 233.02 & 34.19 \\
\hline
\end{tabular}

Triangular signals provided by the DDS for a phase increment of 1 and the corresponding G/S-PAC output voltages are plotted fig. 8 and fig. 9.

\section{CONCLUSION}

A novel phase-to-amplitude converter offering gaussian shape capability together with the more classical sinusoidal shape extends low-cost low-power and high-speed DDS panel of waveform. Our G/S-PAC exhibit an optimal simulated SLRR of $-43.5 \mathrm{dBc}$ in gaussian mode, a SFDR of $-44.5 \mathrm{dBc}$ in sinus mode, and has allowed the design of an ultrahigh-speed $20 \mathrm{GHz}$ simulated DDS with a 9-bit frequency resolution, an 8-bit amplitude resolution, on an IBM $0.13 \mu \mathrm{m}$ BiCMOS SiGe technology.

\section{REFERENCES}

[1] J. Tierney, C. Rader, and B. Gold, A digital frequency synthesizer, Audio and Electroacoustics, IEEE Transactions on, vol. 19, pp. 48 57, mar 1971

[2] X. Geng, F. Dai, J. Irwin, and R. Jaeger, 24-Bit 5.0 GHz Direct Digital Synthesizer RFIC With Direct Digital Modulations in $0.13 \mu \mathrm{m}$ SiGe BiCMOS Technology , Solid-State Circuits, IEEE Journal of, vol. 45, pp. $944-954$, may 2010.

[3] X. Geng, X. Yu, F. Dai, J. Irwin, and R. Jaeger, An 11-bit $8.6 \mathrm{GHz}$ direct digital synthesizer MMIC with 10-bit segmented nonlinear DAC, in Proc. 34th European Solid-State Circuits Conference ESSCIRC 2008, pp. 362-365, 15-19 Sept. 2008.

[4] G. Chen, D. Wu, Z. Jin, and X. Liu, An ultra-high-speed direct digital synthesizer MMIC, in Microwave and Millimeter Wave Technology (ICMMT), 2010 International Conference on, pp. 217 -220, 8-11 2010

[5] S. Turner and D. Kotecki, Direct Digital Synthesizer With SineWeighted DAC at 32-GHz Clock Frequency in InP DHBT Technology, IEEE Journal of Solid-State Circuits, vol. 41, pp. 2284-2290, Oct. 2006.

[6] S. Thuries, É. Tournier, A. Cathelin, S. Godet, and J. Graffeuil, A 6GHz Low-Power BiCMOS SiGe:C $0.25 \mu \mathrm{m}$ Direct Digital Synthesizer, Microwave and Wireless Components Letters, IEEE, vol. 18, pp. 46-48, Jan. 2008.

[7] B. Laemmle, C. Wagner, H. Knapp, H. Jaeger, L. Maurer, and R. Weigel, A Differential Pair-Based Direct Digital Synthesizer MMIC With 16.8GHz Clock and 488-mW Power Consumption, Microwave Theory and Techniques, IEEE Transactions on, vol. 58, pp. 1375 -1383, may 2010

[8] R. Meyer, W. Sansen, and S. Peeters, The differential pair as a trianglesine wave converter, Solid-State Circuits, IEEE Journal of, vol. 11, pp. 418-420, Jun 1976.

[9] J. Gerrits and J. Farserotu, Wavelet generation circuit for UWB impulse radio applications , Electronics Letters, vol. 38, pp. 1737 - 1738, 52002.
[10] S. Thuries and É. Tournier, A DDS-oriented phase-to-amplitude converter using a SiGe:C bipolar transistors differential pair, in Proc. IEEE International Workshop on Radio-Frequency Integration Technology: Integrated Circuits for Wideband Communication and Wireless Sensor Networks, pp. 211-214, 30 Nov.-2 Dec. 2005.

[11] K.-H. Baek, E. Merlo, M.-J. Choe, A. Yen, and M. Sahrling, A $1.7 \mathrm{GHz}$ $3 \mathrm{~V}$ direct digital frequency synthesizer with an on-chip DAC in 0.35 $\mu \mathrm{m}$ SiGe BiCMOS , in Solid-State Circuits Conference, 2005. Digest of Technical Papers. ISSCC. 2005 IEEE International, pp. 114-587 Vol. 1, 2005.

[12] X. Yu, F. Dai, Y. Shi, and R. Zhu, 2 GHz 8-bit CMOS ROM-less direct digital frequency synthesizer, Circuits and Systems, 2005. ISCAS 2005. IEEE International Symposium on, pp. 4397-4400 Vol. 5, May 2005.

[13] P. H. Saul and D. G. Taylor, A high-speed direct frequency synthesizer, Solid-State Circuits, IEEE Journal of, vol. 25, no. 1, pp. 215-219, 1990

[14] F. Dai, L. Chimakurthy, D. Yang, J. Huang, and R. Jaeger, A low power $5 \mathrm{GHz}$ direct digital synthesizer designed in SiGe technology, in Proc. Digest of Papers Silicon Monolithic Integrated Circuits in RF Systems 2004 Topical Meeting on, pp. 21-24, 8-10 Sept. 2004.

[15] A. Gutierrez-Aitken, J. Matsui, E. Kaneshiro, B. Oyama, D. Sawdai, A. Oki, and D. Streit, Ultrahigh-speed direct digital synthesizer using InP DHBT technology, IEEE Journal of Solid-State Circuits, vol. 37, pp. 1115-1119, Sep 2002.

[16] S. Turner and D. Kotecki, Direct digital synthesizer with ROM-Less architecture at $13-\mathrm{GHz}$ clock frequency in InP DHBT technology, IEEE Microwave and Wireless Components Letters, vol. 16, pp. 296-298, May 2006.

[17] H. C. Yeoh, J.-H. Jung, Y.-H. Jung, and K.-H. Baek, A 1.3-GHz 350$\mathrm{mW}$ Hybrid Direct Digital Frequency Synthesizer in 90-nm CMOS , Solid-State Circuits, IEEE Journal of, vol. 45, pp. 1845 -1855, sept. 2010.

[18] B. Laemmle, C. Wagner, H. Knapp, L. Maurer, and R. Weigel, A $366 \mathrm{~mW}$ direct digital synthesizer at $15 \mathrm{GHz}$ clock frequency in SiGe Bipolar technology, in Proc. IEEE Radio Frequency Integrated Circuits Symp. RFIC 2009, pp. 415-418, 2009. 